\title{
PENERAPAN MODEL PEMBELAJARAN KOOPERATIF TIPE STAD METODE SIMULASI TERHADAP HASIL BELAJAR KOGNITIF PESERTA DIDIK
}

\author{
Nurlinda Dahlan ${ }^{1, \mathrm{a}}$, Nur Aisyah Humairah ${ }^{2, \mathrm{~b}}$, Dewi Sartika ${ }^{3, \mathrm{c}}$ \\ 1,2,3,4 Universitas Sulawesi Barat \\ e-mail: ${ }^{\mathrm{a} n u r l i n d a d a h l a n 24 @ g m a i l . c o m},{ }^{\mathrm{b}}$ nuraisyah.humairah@unsulbar.ac.id, $\underline{\text { dewi.sartika@ } \mathrm{unsulbar} . a c . i d}$
}

\begin{abstract}
Abstrak
Tujuan penelitian ini adalah (1) untuk mengetahui hasil belajar kognitif sebelum dan setelah diterapkan Model Pembelajaran Kooperatif Tipe Student Teams Achievement Divisions (STAD) melalui Metode Simulasi, (2) untuk mengetahui hasil belajar kognitif setelah diterapkan Model Pembelajaran Kooperatif Tipe Student Teams Achievement Divisions (STAD) melalui Metode Simulasi serta (3) untuk mengetahui apakah terdapat perbedaan yang signifikan antara hasil belajar kognitif fisika peserta didik kelas XI IPA SMA Negeri 1 Campalagian sebelum dan setelah diterapkan Model Pembelajaran Kooperatif Tipe Student Teams Achievement Divisions (STAD) melalui Metode Simulasi. Jenis penelitian ini adalah Pre-Eksperimen yang menggunakan desain. Sampel penelitian adalah peserta didik kelas XI IPA 2 SMAN 1 Campalagian pada semester ganjil tahun ajaran 2017/2018, dengan jumlah 29 peserta didik. selanjutnya tes pilihan ganda untuk hasil belajar kognitif fisika, teknik analisis data menggunakan analisis deskriptif untuk penilaian model pembelajaran, hasil belajar fisika dan analisis inferensial untuk hasil belajar kognitif fisika. Dari hasil deskriptif diperoleh skor rata-rata pretest sebesar 10,22 dan skor rata-rata posttest sebesar 15,6. Hasil analisis inferensial melalui uji-t menunjukkan bahwa $t_{\text {hitung }}=8,675$ dan $t_{\text {tabel }}=2,048$. Karena $t_{\text {hitung }}>t_{\text {tabel }}$ maka $H_{a}$ diterima. Dengan demikian dapat diketahui bahwa (1) hasil belajar kognitif fisika peserta didik sebelum diterapkan Model Pembelajaran Kooperatif Tipe STAD (Student Teams Achievement Divisions) melalui metode simulasi berada pada kategori sedang, (2) hasil belajar fisika peserta didik setelah diterapkan Model Pembelajaran Kooperatif Tipe STAD (Student Teams Achievement Divisions) melalui metode simulasi berada pada kategori sangat tinggi dan (3) terdapat perbedaan yang signifikan antara hasil belajar kognitif peserta didik kelas XI IPA SMA Negeri 1 Campalagian sebelum dan setelah diterapkan Model Pembelajaran Kooperatif Tipe STAD (Student Teams Achievement Divisions) melalui metode simulasi.
\end{abstract}

Kata Kunci: Model pembelajaran kooperatif, Model pembelajaran Teams Achievement Divisions (STAD), Metode simulasi, Hasil belajar fisika.

\section{IMPLEMENTATION OF STAD TYPE COOPERATIVE LEARNING MODEL SIMULATION METHODS OF LEARNERS COGNITIVE LEARNING OUTCOMES}

\begin{abstract}
The aims of this study were (1) to determine cognitive learning outcomes before and after the implementation of the Student Teams Achievement Divisions (STAD) Cooperative Learning Model through the Simulation Method, (2) to determine cognitive learning outcomes after the Student Teams Achievement Divisions (Cooperative Learning Model) was applied. STAD) through the Simulation Method and (3) to find out whether there is a significant difference between the students' cognitive physics learning outcomes in class XI IPA SMA Negeri 1 Campalagian before and after the Cooperative Learning Model Type Student Teams Achievement Divisions (STAD) was applied through the Simulation Method. This type of research is a Pre-Experiment using a design. The research sample was students of class XI IPA 2 of SMAN 1 Campalagian in the odd semester of the 2017/2018 academic year, with a total of 29 students. then multiple
\end{abstract}


choice test for cognitive physics learning outcomes, data analysis techniques using descriptive analysis for the assessment of learning models, physics learning outcomes and inferential analysis for cognitive physics learning outcomes. From the descriptive results, the average pretest score was 10.22 and the posttest average score was 15.6. The results of inferential analysis through $t$-test showed that tcount $=8,675$ and ttable $=2,048$. Because tcount $>$ ttable then Ha is accepted. Thus it can be seen that (1) the students' cognitive physics learning outcomes before the STAD Type Cooperative Learning Model (Student Teams Achievement Divisions) is applied through the simulation method are in the medium category, (2) students' physics learning outcomes after the STAD Type Cooperative Learning Model is applied. (Student Teams Achievement Divisions) through the simulation method is in the very high category and (3) there is a significant difference between the cognitive learning outcomes of class XI IPA students at SMA Negeri 1 Campalagian before and after the STAD (Student Teams Achievement Divisions) Cooperative Learning Model is applied. through the simulation method.

Keywords: Cooperative learning model, Teams Achievement Divisions (STAD) learning model, Simulation method, Physics learning outcomes.

\section{PENDAHULUAN}

Sekolah adalah wadah yang tepat untuk membentuk dan membina peserta didik menjadi sumber daya manusia yang terdidik dan terlatih dengan pengajaran yang profesional dan proporsional. Hal ini tercantum di salah satu misi SMAN 1 Campalagian yaitu proses belajar mengajar dilaksanakan secara profesional dan proporsional yaitu dengan pendekatan manusiawi, pendekatan sosial budaya dan pendekatan kasih sayang sehingga menciptakan manusia yang sopan santun, cerdas, berprestasi serta berdaya saing.

misi tersebut SMAN 1 Campalagian menggunakan tenaga pendidik dari beberapa golongan salah satunya yaitu magister yang dapat meningkatkan mutu pendidikan atau hasil belajar yang lebih baik. Hasil belajar merupakan indikator yang penting untuk mengukur keberhasilan proses pembelajaran. Hasil belajar juga dapat menjadi tolak ukur dari tingkatan pemahaman peserta didik terhadap materi tertentu yang telah diberikan setelah peserta didik mengalami proses belajar pada jangka waktu tertentu dan dinyatakan dalam bentuk nilai. Sehingga dapat dikatakan bahwa hasil belajar adalah hasil yang diperoleh peserta didik setelah mempelajari materi pelajaran yang diwujudkan melalui perubahan reaksi dan sikap peserta didik.

Hal ini sesuai dengan observasi awal pada tanggal 18 Januari 2017, di SMAN 1 Campalagian berupa wawancara dari guru mata pelajaran fisika bahwa nilai hasil ulangan tengah semester peserta didik tergolong rendah yaitu 60 .
Nilai tersebut masih di bawah standar ketuntasan atau nilai KKM yang ditentukan oleh sekolah yaitu 75. [14].

Kemudian dilakukan observasi selanjutnya, pada observasi tersebut dilakukan pembagian kuesioner berupa pertanyaanpertanyaan terkait dengan pelajaran fisika disertai dengan keluhan mengenai pelajaran fisika di kelas XI IPA 2. Dari hasil observasi ditemukan banyak peserta didik yang menjawab bahwa fisika itu susah, rumit, membosankan, menakutkan dan memusingkan sehingga peserta didik cenderung pasif dalam menerima pembelajaran bahkan ada juga peserta didik yang tidak suka dengan cara mengajar gurunya yang terkesan membosankan dan kurang efektif dalam menyampaikan materinya. Bahkan seringkali peserta didik kurang perhatian dari guru pada saat menjelaskan karena guru keasyikan sendiri dalam menjelaskan sehingga membuat peserta didik hilang konsentrasi menjadi tidak mengerti apa yang disampaikan oleh gurunya, yang pada akhirnya menyebabkan hasil belajar fisika rendah.

Sehingga dibutuhkan solusi untuk mengatasi permasalahan tersebut dengan menerapkan model pembelajaran yang menitikberatkan keaktifan peserta didik salah satunya yaitu model pembelajaran kooperatif tipe STAD (Student Team Achievement Division).

Model pembelajaran kooperatif tipe STAD (Student Team Achievement Division) merupakan salah satu model pembelajaran kooperatif yang membagi peserta didik di dalam 
kelas menjadi beberapa kelompok atau tim, masing-masing terdiri atas empat atau lima anggota kelompok yang anggotanya heterogen, baik jenis kelamin maupun kemampuan (rendah, sedang, \& tinggi) [4]. Hal tersebut dapat mengkondisikan suasana lingkungan yang nyaman bagi peserta didik dalam proses pembelajaran.

Pernyataan tersebut didukung oleh hasil penelitian yang dilakukan oleh [8] yang menyimpulkan bahwa pengaruh model pembelajaran kooperatif tipe STAD ( Student Team Achievement Division) dapat meningkatkan hasil belajar peserta didik di SMA Swasta Santo Thomas 3. Setiap orang harus melakukan belajar dengan sungguh-sungguh dalam hidupnya untuk mencapai apa yang akan dicita-citakan. Belajar adalah suatu proses usaha yang dilakukan seseorang untuk memperoleh suatu perubahan tingkah laku yang baru secara keseluruhan sebagai hasil pengalamannya sendiri dalam interaksi dengan lingkungannya [8].

Jadi dapat disimpulkan bahwa belajar adalah suatu proses mental yang terjadi dalam diri seseorang dan melibatkan kegiatan berfikir yang terjadi melalui interaksi dengan lingkungan (pengalaman belajar) sehingga terjadi perubahan perilaku yang positif

Pembelajaran kooperatif adalah sistem pengajaran yang memberi kesempatan kepada anak didik untuk bekerja sama dengan sesama peserta didik dalam tugas-tugas yang terstruktur [8]. Ciri-ciri pembelajaran kooperatif yaitu [6] peserta didik bekerja sama dalam kelompok secara kooperatif untuk memutuskan materi belajarnya, kelompok dibentuk dari peserta didik yang memiliki kemampuan tinggi, sedang dan rendah, Bila mungkin anggota kelompok berasal dari ras, budaya, suku, jenis kelamin yang berbeda-beda, dan Penghargaan lebih berorientasi kelompok daripada individu.

Pembelajaran kooperatif tipe STAD (Student Team Achievement Division) merupakan model pembelajaran kooperatif yang paling sederhana. Guru membagi peserta didik menjadi kelompok-kelompok kecil yang terdiri dari 4-5 orang siswa yang terdiri laki- laki dan perempuan yang berasal dari berbagai suku, memiliki kemampuan tinggi, sedang, rendah.
Pembelajaran kooperatif tipe STAD (Student Team Achievement Division) terdiri dari 5 komponen utama, yaitu (1) penyajian kelas, (2) belajar kelompok, (3) tes, (4) skor peningkatan individual, (5) penghargaan kelompok [11]. Kata simulation artinya tiruan atau perbuatan yang pura-pura dengan demikian simulasi dalam metode mengajar di maksudkan sebagai cara untuk menjelaskan (bahan pelajaran) melalui perbuatan yang bersifat berpura-pura atau melalui proses tingkah laku imitasi atau bermain peranan mengenai suatu tingkah laku yang di lakukan seolah-olah dalam kedaan yang sebenarnya.

Belajar dan mengajar sebagai suatu proses mengandung tiga unsur yang dapat dibedakan, yakni tujuan pengajaran (instruksional), (pengalaman) (proses) belajar mengajar dan hasil belajar. Hasil belajar adalah kemampuan- kemampuan yang dimiliki peserta didik setelah ia menerima pengalaman belajarnya. Kemampuan -kemampuan tersebut sesuai dengan aspek kognitif, afektif dan psikomotor. Howard Kingsley dalam Sudjana membagi hasil belajar menjadi tiga macam yaitu (a) keterampilan dan kebiasaan, (b) pengetahuan dan pengertian, (c) sikap dan cita-cita. [15]

Ranah kognitif adalah mengenai kemampuan intelektual peserta didik seperti yang ditampakkan dalam menyelesaikan soalsoal fisika [7]. Menyusun suatu karangan, atau dalam menyesuaikan berbagai jenis soal yang membutuhkan "pemikiran". Model pembelajaran kooperatif tipe Student TeamsAchievement Divisions (STAD) merupakan salah satu model dalam pembelajaran kooperatif yang sederhana dan baik untuk guru yang baru mulai menggunakan pendekatan kooperatif dalam kelas [12].

Model pembelajaran kooperatif tipe STAD ( Student Team Achievement Division) adalah merupakan salah satu tipe pembelajaran kooperatif yang digunakan oleh guru-guru yang baru mulai menggunakan pembelajaran kooperatif [1]. Guru menyajikan pelajaran kemudian peserta didik bekerja di kelompok mereka untuk memastikan bahwa seluruh anggota kelompok telah menguasai materi tersebut. Gagasan utama dai STAD (Student Team Achievement Division) adalah untuk 
memotivasi peserta didik supaya dapat saling mendukung dan saling kerja sama dalam menguasai kemampuan yang diajarkan oleh guru jika peserta didik ingin agar timnya mendapatkan penghargaan tim, maka mereka harus membantu teman satu timnya untuk mempelajari materinya.

\section{METODE}

Jenis penelitian yang digunakan dalam penelitian ini adalah penelitian pre eksperimental yang menghubungkan desain eksperimental yang menggunakan desain OneGroup Pretest-Posttest sebagai berikut:

$\begin{array}{lll}\mathbf{O}_{1} & \mathbf{X} & \mathbf{O}_{2}\end{array}$

Keterangan :

$\mathrm{O}_{1}$ :Pengukuran

(Sebelum

diberi perlakuan/posttest)

$\mathrm{X}$ :Perlakuan (model discovery learning dengan teknik probing prompting)

$\mathrm{O}_{2}$ :Pengukuran diberi perlakuan/posttest)

Populasi dalam penelitian ini adalah seluruh peserta didik kelas XI IPA SMA Negeri 1 Campalagian tahun ajaran 2017/2018 yang berjumlah 178 orang.

\section{Validasi Instrumen}

Instrumen tes kemampuan kognitif yang digunakan dalam penelitian ini, terlebih dahulu dinilai oleh dua orang ahli dan hasil penilaian dari kedua ahli tersebut kemudian dianalisis dengan menggunakan validitas isi secara keseluruhan yang dikemukakan oleh Gregory. Koefisien validitas isi tersebut dihitung dengan menggunakan rumus Gregory sebagai berikut [9]:

Validasi isi $=\frac{D}{(A+B+C+D)}$

Berdasarkan ketentuan dari kesepakatan antara ahli untuk validasi isi bahwa item dengan status D dapat langsung digunakan, untuk ite, dengan status C dan B akan dikoreksi lagi sebelum digunakan, sedangkan untuk item dengan status A akan langsung dibuang [5]. Adapun kategori validitas isi dapat dilihat pada tabel berikut:

Tabel 1. kategori validitas

\begin{tabular}{ll}
\hline Interval & Kriteria \\
\hline $0,80-1,00$ & Sangat tinggi \\
\hline $0,60-0,79$ & Tinggi \\
\hline $0,40-0,59$ & Sedang \\
\hline $0,20-0,39$ & Rendah \\
\hline $0,00-0,19$ & Sangat rendah \\
\hline
\end{tabular}

\section{Teknik Analisis Data}

Teknik Analisis Deskriptif

Berikut rumus yang digunakan adalah

Skor Rata-Rata $(\underline{X})$

$\bar{X}=\frac{\sum f_{1} K_{1}}{\sum f_{1}}$

Standar Deviasi $\left(S_{\mathrm{d}}\right)$ :

$S_{d}=\sqrt{\frac{\sum f_{1}\left(K_{1}-\bar{K}\right)^{2}}{n-1}}$

\section{Perolehan Nilai}

Untuk mengetahui nilai yang diperoleh peserta didik, maka skor dikoneksi ke nilai dengan menggunakan rumus :

Nilai $=\frac{\text { skor peserta didik }}{\text { skor maksimum }} \times 100$

Berdasarkan hasil pretest dan posttest ditinjau dari indikator untuk ranah kognitif $\mathrm{C} 1, \mathrm{C} 2, \mathrm{C} 3$, dan C4 dilihat sebagai berikut:

Tabel 2. kategori Penilaian Aspek Kognitif

\begin{tabular}{lll}
\hline No & $\begin{array}{l}\text { Interval } \\
\text { Nilai }\end{array}$ & Keterangan \\
\hline 1 & $81-100$ & $\begin{array}{l}\text { Sangat Tinggi } \\
(\text { ST) }\end{array}$ \\
\hline 2 & $61-80$ & Tinggi (T) \\
\hline 3 & $40-60$ & Sedang (S) \\
\hline 4 & $21-40$ & Rendah (R) \\
\hline 5 & $0-20$ & $\begin{array}{l}\text { Sangat Rendah } \\
(\text { SR) }\end{array}$ \\
\hline
\end{tabular}

(SR) 
Nilai Keterlaksanaan penerapan model pembelajaran dapat ditentukan dengan menggunakan persamaan berikut [6]:

Nilai $=\frac{\sum \text { Penilaian tiap aspek }}{\sum \text { Aaspek }}$

Tabel 3. Skala Penilaian Keterlaksanaan

Penerapan Model Pembelajaran

\begin{tabular}{cc}
\hline Nilai & Kriteria \\
\hline 5 & Sangat Baik \\
\hline 4 & Baik \\
\hline 3 & Cukup Baik \\
\hline 2 & Kurang Baik \\
\hline 1 & Tidak Baik \\
\hline
\end{tabular}

\section{Teknik Analisis Inferensial}

Analisis statistik inferensial digunakan untuk menguji hipotesis penelitian penelitian, Sebelum hipotesis terlebih dahulu dilakukan uji prasyarat yaitu uji normalitas

\section{Uji Normalitas}

Pengujian normalitas dalam penelitian ini menggunakan rumus Chi- Kuadrat sebagai berikut [10]:

$3^{2}=\sum_{i=1}^{K} \frac{\left(f_{0}-f_{e}\right)^{2}}{f_{e}}$

Kriteria pengujian: Data berdistribusi normal bila $X_{\text {hiting }}^{2}$ lebih kecil dari $X_{\text {tabel }}^{2}$ dimana daftar $X^{2}$ dengan $d k=(k-1)$ pada taraf signifikan $\alpha=0,05$.

\section{Uji Hipotesis}

Pengujian hipotesis pada penelitian ini menggunakan uji-t, dengan $\alpha=0,05$. yaitu [2]:

$t=\frac{M d}{\sqrt{\frac{\sum X d^{2}}{N(N-1)}}}$

Kriteria pengujian untuk uji $\mathrm{t}$ adalah sebagai berikut:

$t_{\text {hitung }} \leq t_{\text {tabel }}$, maka $\mathrm{H}_{0}$ diterima $t_{\text {hiting }}>$ $t_{\text {tabel }}$, maka $\mathrm{H}_{\mathrm{a}}$ diterima [19].

Uji hipotesis dilakukan untuk menjawab hipotesis penelitian. Hipotesis pada penelitian ini sebagai berikut:

$\mathrm{H}_{\mathrm{o}}$ : Tidak terdapat perbedaan signifikan antara kemampuan kognitif peserta didik XI IPA SMA Negeri 1 Campalagian sebelum dan setelah diterapkan model pembelajaran kooperatif tipe STAD (Students Teams Achievement Division) melalui model simulasi.

$\mathrm{H}_{\mathrm{a}}$ : Terdapat perbedaan signifikan antara kemampuan kognitif peserta didik kelas XI IPA SMA Negeri 1 Campalagian sebelum dan setelah diterapkan model pembelajaran kooperatif tipe STAD (Students Teams Achievement Division) melalui metode simulasi.

Adapun rumus hipotesis yaitu sebagai berikut [13]:

$$
\begin{gathered}
H_{o}: \mu_{1}=\mu_{2} \\
H_{a}: \mu_{1} G \mu_{2}
\end{gathered}
$$

$\mu_{1}$ : Skor rata-rata hasil kemampuan kognitif peserta didik kelas XI IPA SMA Negeri 1 Campalagian sebelum model pembelajaran kooperatif tipe STAD (Students Teams Achievement Division) melalui metode simulasi.

$\mu_{2}$ : Skor rata-rata hasil kemampuan kognitif peserta didik kelas XI IPA SMA Negeri 1 Campalagian setelah diterapkan model pembelajaran kooperatif tipe STAD (Students Teams Achievement Division) melalui metode simulasi

\section{HASIL DAN DISKUSI}

Berdasarkan hasil analisis diperoleh skor rata-rata pretest 10,22 dengan standar deviasi 2,66 yang berarti ukuran penyimpangan data dari skor rata- ratanya kecil dan skor rata-rata Posttest 15,6 dengan standar deviasi 3,01 yang berarti ukuran penyimpanan data dari skor rata-ratanya besar. Nilai hasil kemampuan kognitif fisika yang diperoleh peserta didik untuk posttest ditunjang oleh keterlaksanaan penerapan model pembelajaran kooperatif tipe STAD (Student Team Achievement Division) melalui metode simulasi. Keterlaksanaan model pembelajaran tersebut dinilai oleh seorang observasi yang telah ditetapkan, kemudahan diolah. Adapun nilai yang diperoleh keterlaksanaan penerapan model 
pembelajaran sebagai berikut:

Tabel 4. Keterlaksanaan Pembelajaran Model Pembelajaran

\begin{tabular}{ccc}
\hline Pertemuan & Nilai & Kriteria \\
\hline 1 (Pretest $)$ & - & - \\
\hline 2 & 4 & Baik \\
\hline 3 & 4 & Baik \\
\hline 4 & 4 & Baik \\
\hline 5 & 4 & Baik \\
\hline $6($ Posttest $)$ & - & - \\
\hline
\end{tabular}

(Sumber : Olahan Data)

\section{Hasil}

\section{Uji Normalitas}

Hasil pengujian normalitas data skor kemampuan kognitif peserta didik sebelum diterapkan model pembelajaran Kooperatif Tipe STAD (Student Teams Achievement Division) melalui metode simulasi menunjukan bahwa nilai $X_{\text {hitung }}^{2}=6,14$ lebih kecil dari $X_{\text {tabel }}^{2}=11,07$. Sehingga, data berdistribusi normal. Dimana daftar $X^{2}$ dengan $d k=(k-1)$ pada taraf signifikan $\alpha=0,05$. Hasil perhitungan normalitas setelah diterapkan model pembelajaran kooperatif Tipe STAD (Students Teams Achievement Division) melalui metode simulasi jugas berdistribusi normal karena dari $X^{2}$ dengan $d k=(k-1)$ Pada taraf signifikan $\alpha=0,05$.

Uji Hipotesis

Pengujian hipotesis yang telah diajukan dianalisis digunakan uji-t dengan taraf ketidakpastian 5\% dan $d k=5$, Diperoleh harga $t_{\text {hitung }}=8,675>t_{\text {tabel }}=2,048, \quad$ yang berarti hasil pengujian hipotesis berada pada penolakan $\mathrm{HO}$ dan penerimaan Ha yang berarti terdapat perbedaan signifikan antara kemampuan kognitif peserta didik kelas XI IPA SMA Negeri 1 Campalagian sebelum dan setelah diterapkan model pembelajaran kooperatif tipe STAD (Students Teams Achievement Division) melalui metode simulasi.

\section{SIMPULAN DAN SARAN Simpulan}

Berdasarkan hasil penelitian dan pembahasan, maka dapat disimpulkan bahwa: Hasil belajar kognitif peserta didik kelas XI MIPA SMA Negeri 1 Campalagian sebelum diajar dengan menggunakan model kooperatif tipe STAD (Student Team Achievement Division) melalui metode simulasi, tergolong kategori sedang. Hasil belajar kognitif peserta didik kelas XI IPA SMA Negeri 1 Campalagian sebelum diajar dengan menggunakan model kooperatif tipe STAD (Student Team Achievement Division) melalui metode simulasi, tergolong kategori sangat tinggi. Terdapat perbedaan signifikan antara hasil belajar kognitif peserta didik sebelum dan setelah diajar dengan menggunakan model kooperatif tipe STAD (Student Team Achievement Division) melalui metode simulasi.

\section{Saran}

Sehubungan dengan hasil yang diperoleh dalam penelitian ini, maka penulis mengajukan saran sebagai berikut: Dilihat dari aktivitas peserta didik pada saat belajar kelompok sebagian besar peserta didik kurang fokus. Sehingga hanya sedikit yang memperhatikan. Bagi pengajar diharapkan untuk membimbing peserta didiknya untuk saling kerja sama dalam kelompok agar mereka dapat merasakan saling kerja sama dalam kegiatan kelompok. Mengingat pada saat proses belajar mengajar berlangsung sebagian besar perhatian peserta didik tertuju pada handphone mereka masing-masing sehingga pada saat kita menyampaikan materi hanya sedikit peserta didik yang memperhatikan diharap bagi pihak sekolah untuk lebih memperketat peraturan di sekolah agar peserta didik juga lebih bisa memperhatikan pelajaran yang sedang berlangsung. Yang menjadi masalah juga pada saat proses belajar mengajar ada saja peserta didik yang sering keluar masuk tidak jelas sehingga mengganggu konsentrasi pengajar dan juga terutama peserta didik yang lain diharap juga bagi pengajar maupun dari pihak sekolah untuk memperketat kedisiplinan yang ada di sekolah agar peserta didik tidak seenaknya keluar masuk dari kelas pada saat proses belajar 
mengajar berlangsung agar tidak mengganggu konsentrasi peserta didik yang lain.

\section{DAFTAR PUSTAKA}

[1] Afandi, dkk. 2013. Model dan Metode Pembelajaran di Sekolah. Semarang: Unissula Press.

[2] Arikunto, Suharsimi. 2006. Prosedur Penelitian Suatu Pendekatan Praktik. Jakarta: Rineka Cipta.

[3] Arsyad, Arie Arma. 2015. Pengembangan Perangkat Pembelajaran Beriorentasikan Model Cooperative Problem Solving Pada Pokok Bahasan Optik Untuk Meningkatkan Hasil Belajar Siswa SMP (Tesis Tidak dipublikasikan). Surabaya: Universitas Negeri Surabaya.

[4] Giantara, dkk. 2016. Pengaruh Penerapan Model Pembelajaran Kooperatif Tipe STAD (Student Team Achievement Division) Terhadap Hasil Belajar Matematika Siswa Kelas V SD Gugus V Kecamatan Marga. Jurnal Mimbar PGSD Universitas Pendidikan Ganesha Vol: 2 No: 1 Tahun 2014.

[5] Humairah, Nur Aisyah. 2010. Implementasi Kurikulum Tingkat Satuan Pendidikan Dalam Pembelajaran Fisika Pada SMP Negeri Di Kabupaten Polewali Mandar (Tesis Tidak dipublikasikan).Makassar: Universitas Negeri Makassar.

[6] Ibrahim, M. 2005. Assesmen Berkelanjutan. Surabaya: Unipress Unesa.

[7] Khaeruddin \& Ali, Sidin. 2012. Evaluasi Pembelajaran. Makassar: Badan Penerbit UNM.

[8] Lubis, Asneli . 2011. Pengaruh Model Pembelajaran Kooperatif Tipe STAD (Student Team Achievement Division) Terhadap Hasil Belajar Fisika siswa pada Materi Pokok Gerak Lurus Di Kelas X SMA Swasta Uisu Medan. Jurnal.Pendidikan Fisika, ISSN 2252$732 \mathrm{X}$.

[9] Retnawati, Heri. 2016. Analisis Kuantitatif Instrumen Penelitian. Yogyakarta: Parama Publishing.

[10] Sugiyono, 2005. Statistika untuk
Penelitian. Bandung: Alfabeta.

[11] Sumuri, Indawati, 2012. Penerapan Model Pembelajaran Kooperatif Tipe STAD (Student Team Achievement Division) Untuk Meningkatkan Hasil Belajar Siswa Pada Materi Energi Panas Di Kelas IV SD Inpres Siuna. Jurnal Kreatif Tadulako Online Vol. 4 No. 12. ISSN 2354- 614 X.

[12] Susanti, dkk. 2015. Pengaruh Model Pembelajaran Kooperatif Tipe STAD (Student Team Achievement Division) Terhadap Hasil Belajar Kognitif Fisika Siswa SMK N 1 Rambah Tahun Pembelajaran 2014/2015. Jurnal Universitas Pasir Pengaraian.

[13] Susetyo, Budi. 2017. Statistika Untuk Analisis Data Penelitian. Bandung :Refika Aditama.

[14] SMAN 1 Campalagian. (2017). Informasi Dan Data Siswa. Campalagian.

[15] Wisnungkoro, Dimas. 2014. Pengaruh Metode Simulasi Terhadap Hasil Belajar Dribble Sepak Bola ( Studi Pada Siswa Kelas VIII SMP) Negeri 3 Trenggalek). Jurnal Universitas Negeri Surabaya. 